\title{
BBEP
}

\section{Discutindo combinatória em um processo de formação continuada com professores dos anos iniciais}

\author{
Adryanne Maria Rodrigues Barreto de Assis, II \\ Cristiane Azevêdo dos Santos Pessoa ${ }^{\text {III, IV }}$
}

http://dx.doi.org/10.1590/S2176-6681/340513313

\section{Resumo}

Propõe analisar o efeito de uma formação continuada baseada nas situações, nos invariantes e nas representações simbólicas dos problemas combinatórios. A pesquisa constitui-se em entrevista inicial individual, quatro encontros de formação e, em seguida, entrevista final, também individual, com os professores participantes. Para este artigo, analisa-se o desenvolvimento de uma professora participante do processo. Os resultados apontam dificuldade no reconhecimento e na abordagem de combinatória na entrevista inicial, no entanto, após as intervenções, há o reconhecimento mais detalhado das diferentes situações e seus invariantes, assim como das representações. Percebe-se, assim, que a formação continuada em combinatória pode se constituir em uma ação importante, pois estimula os docentes a refletirem sobre esse conteúdo, que pode ser trabalhado desde os anos iniciais.

Palavras-chave: combinatória; formação continuada; anos iniciais de escolarização; professores.

Faculdade Metropolitana da Grande Recife (FMGR), Recife, Pernambuco, Brasil.

E-mail: adryanne@gmail.com

II Mestre em Educação Matemática e Tecnológica pela Universidade Federal de Pernambuco (UFPE), Recife, Pernambuco, Brasil.

III Universidade Federal de Pernambuco (UFPE), Recife, Pernambuco, Brasil.

E-mail: cristianepessoa74@ gmail.com

IV Doutora em Educação pela Universidade Federal de Pernambuco (UFPE), Recife, Pernambuco, Brasil. 


\section{Abstract \\ Discussing combinatorics in a process of continuing education with early grade teachers}

The study aims to analyze the effect of continuing education based on situations, invariants and symbolic representations of combinatorial problems. This research is composed of initial individual interviews, four formation meetings and a final interview, also individual, with the participant teachers. In this article, we analyze the development of a teacher taking part in the process. The results indicate a difficulty in the recognition and in the approach of combinatorics during the initial interview; however, after the interventions, there is a more detailed recognition of different situations and their invariants, as well as of representations. It is clear; therefore, that continuing education in combinatorics may constitute an important action because it stimulates teachers to reflect about this content, which can be used from initial grades on.

Keywords: combinatorics; continuing education; early primary grades; teachers.

\section{O ensino da combinatória e a formação de professores}

Os livros didáticos dos anos iniciais do ensino fundamental (EF), de acordo com Barreto, Amaral e Borba (2007), já trazem problemas combinatórios dos diferentes tipos. De acordo com Rocha (2011), professores dos anos iniciais apresentam dificuldades conceituais e didáticas ao refletirem sobre combinatória. Acreditamos que essa dificuldade se deve, também, ao parco trabalho específico com o conteúdo durante suas formações iniciais. Além disso, são poucas as alternativas metodológicas apresentadas aos futuros professores para o trabalho com esse conteúdo, de sorte que estes nem sempre conseguem criar condições facilitadoras e desenvolver um processo dinâmico de ensino, que possibilite a aprendizagem desse conhecimento. Isso faz com que, na maioria das vezes, o professor deixe de abordá-lo na sala de aula.

Dessa forma, uma vez que faltam aos professores em sua formação inicial a abordagem e a reflexão acerca do ensino de conteúdos específicos, como a combinatória, apresenta-se a necessidade de constantes encontros sobre esses conteúdos para que haja formação continuada. Surge, assim, a necessidade de investigar o processo de formação continuada de professores "como medida concreta para aperfeiçoar, de forma permanente, a competência docente" (Fusari, 1992, p. 29).

Rocha (2011) buscou verificar quais conhecimentos sobre combinatória professores de diferentes níveis de ensino trazem para a sala de aula, 
abordando aqueles que Shulman (2005) defende como necessários para uma knowledge base (base de conhecimentos). Assim, investigaremos os saberes dos professores segundo essa perspectiva.

Essa base de conhecimentos, para Shulman (2005), é constituída por diferentes categorias, quais sejam: 1) conhecimento do conteúdo; 2) conhecimento didático geral - princípios e estratégias de organização da classe que transcendem o âmbito da disciplina; 3) conhecimento do currículo - materiais e programas que servem como ferramentas de auxílio para o docente; 4) conhecimento didático do conteúdo combinação de conteúdo e pedagogia, no sentido de transpor o conteúdo para o ensino, constituindo uma esfera exclusiva dos professores; 5) conhecimento dos alunos e suas características; 6) conhecimento dos contextos educativos - abrangem desde o funcionamento da sala de aula, a gestão e o financiamento dos distritos escolares até o caráter das comunidades e culturas; 7) conhecimento dos objetivos, das finalidades, dos valores educativos e de seus fundamentos filosóficos e históricos.

Entre as categorias elencadas como formadoras da base do conhecimento, Shulman (2005) destaca o conhecimento didático do conteúdo, considerando que a partir desse conhecimento é possível distinguir a compreensão de um especialista da área e a compreensão de um professor a respeito de um determinado assunto.

Há ainda outros estudos com relação à combinatória, entre os quais destacamos: Pessoa e Borba (2010), que buscaram levantar a compreensão de problemas combinatórios por alunos da $1^{\mathrm{a}}$ série (atual $2^{\circ}$ ano) do EF ao $3^{\circ}$ ano do ensino médio, observando as estratégias por eles utilizadas; Azevedo, Costa e Borba (2011), que se propuseram verificar se o uso do software Árbol pode ajudar na compreensão de problemas combinatórios; e Santos, Matias e Pessoa (2011), que investigaram se crianças da educação infantil percebem os invariantes dos diferentes tipos de problemas ao resolverem problemas combinatórios.

Entre as variadas temáticas pesquisadas, interessamo-nos especificamente pela formação continuada de professores, pelo ensino de combinatória e pelo processo de construção do raciocínio combinatório. Acreditamos que, se as situações ${ }^{1}$, os invariantes e as representações simbólicas ${ }^{2}$ envolvidos em um conceito forem percebidos, a interpretação e a compreensão de um problema por parte do aluno mudarão.

De acordo com o levantamento bibliográfico realizado, muitos estudos foram organizados no sentido de verificar como se dá o ensino e a compreensão de combinatória em diferentes idades e níveis de escolaridade (Pessoa; Borba, 2010; Santos; Matias; Pessoa, 2011; Rocha, 2011; Pessoa; Santos, 2012a; Azevedo; Borba, 2012; Santos; Pessoa, 2014, entre outros), no entanto, não haviam sido elaborados estudos que verificassem a influência de um processo de formação continuada, tendo por base a compreensão das situações, dos invariantes e das representações do conceito de combinatória no conhecimento de um professor.

\footnotetext{
Estamos, neste estudo, usando situações combinatórias como sinônimo de tipos de problemas combinatórios.

2 Situações, invariantes e representações simbólicas são, para Vergnaud (1986), o tripé que forma o conceito. Esse assunto será discutido adiante.
} 


\section{O raciocínio combinatório e a formação de conceitos}

A combinatória é uma área da matemática que faz parte do raciocínio multiplicativo. Apesar de os Parâmetros Curriculares Nacionais (PCN) (Brasil, 1997) apontarem a necessidade de tal conteúdo ser trabalhado desde os anos iniciais da escolaridade, essa indicação, de um modo geral, ainda não é completamente seguida no trabalho escolar.

Vergnaud (1986) tem como premissa que o conhecimento está organizado em campos conceituais, cujo domínio, por parte do sujeito, ocorre ao longo de um extenso período de tempo, por meio de experiência, maturidade e aprendizagem. Portanto, faz-se importante o ensino dos diferentes tipos de problemas combinatórios durante toda a vida escolar.

Ainda de acordo com o autor, há três dimensões fundamentais para a formação do conceito, que devem ser consideradas no aprendizado: (1) o conjunto de situações que dão significado ao conceito (S); (2) as relações e propriedades invariantes (I); e (3) o conjunto das representações simbólicas utilizadas para a resolução do problema (R).

De acordo com a teoria dos campos conceituais de Vergnaud, Pessoa e Borba (2009) organizam os problemas que abrangem o raciocínio combinatório e as características particulares de cada tipo de problema. A seguir, no Quadro 1, apresentamos as situações presentes em combinatória (produto cartesiano, arranjo, permutação e combinação) e seus respectivos invariantes.

\section{Quadro 1 - Situações e Invariantes da Combinatória}

Produto Cartesiano: (1) dois (ou mais) conjuntos diferentes serão combinados para construir um novo grupo; (2) diferentemente dos demais tipos de problema, a ordem dos elementos poderá ou não gerar novas possibilidades.

Arranjo: (1) um grupo maior gerará novas possibilidades ao subgrupo e não são utilizados todos os elementos do grupo maior; (2) a ordem e a escolha dos elementos geram novas possibilidades.

Permutação: (1) todos os elementos são utilizados, cada um, apenas uma vez; (2) a ordem dos elementos do conjunto gera novas possibilidades.

Combinação: (1) de um conjunto maior, serão selecionados objetos ou situações que constituirão subgrupos; (2) a ordem dos objetos escolhidos não gerará novas possibilidades.

Fonte: Pessoa e Borba, 2009.

As representações podem ser expressas mediante estratégias utilizadas pelos alunos, tais como árvores de possibilidades, listagens, diagramas, fórmulas ou contas armadas, por exemplo.

Assim, são necessários estudos que verifiquem como se dá o processo de construção e percepção das situações, dos invariantes e das representações simbólicas de cada tipo de problema pelos professores, em encontros de formação, para que estes possam (re)significar seu 
conhecimento acerca desse conteúdo e refletir sobre como transpassá-lo para o conhecimento didático durante o processo de ensino.

\section{O caminhar do processo: objetivos e método}

Diante do exposto, percebe-se como é importante refletir sobre o ensino de combinatória. Para isso, tendo como base o processo de formação continuada, a pesquisa realizada girou em torno do seguinte questionamento:

- Um processo de formação continuada, baseado nas situações, nos invariantes e nas representações simbólicas de combinatória, influenciaria nos conhecimentos de professores dos anos iniciais do EF?

Assim, o objetivo do presente estudo é analisar o efeito de uma formação continuada em combinatória, baseada nas situações, nos invariantes e nas representações simbólicas dos problemas combinatórios, sobre professores dos anos iniciais do EF.

Apesar de todo o processo da formação ter ocorrido com quatro professoras do turno vespertino de uma escola pública municipal de Recife, no presente artigo será apresentada a análise do processo de formação de uma professora. ${ }^{3}$

Inicialmente, foi realizada uma entrevista semiestruturada individual; em seguida, um processo de formação continuada; e, por fim, outra entrevista semiestruturada, a fim de constatar qual compreensão de combinatória, enquanto conteúdo escolar, foi desenvolvida após a participação no processo de formação realizado. As entrevistas semiestruturadas foram baseadas em Rocha (2011). ${ }^{4}$

A formação consistiu em quatro encontros, nos quais foram enfatizadas as situações, os invariantes e as representações simbólicas existentes em cada tipo de problema combinatório, como explicitado nos Quadros 2, 3, 4 e 5.

Cada entrevista foi dividida em três eixos: Formação e Experiência Docente, Conhecimento Didático de Combinatória e Conhecimento do Conteúdo de Combinatória. Na entrevista inicial, esses eixos se subdividem em sete momentos, com os objetivos de: (1) identificar, conhecer e obter informações gerais sobre o professor entrevistado; (2) conhecer e entender as experiências e os fatos da vida profissional, como também da vida escolar do professor, e se estes influenciam na sua prática docente, em relação ao ensino de combinatória; (3) investigar os saberes matemáticos e didáticos do professor quanto à combinatória e, assim, entender como o professor pesquisado compreende o ensino desse tema nos anos iniciais e procede em relação a ele; (4) diferenciar os problemas combinatórios com base em situações e invariantes; (5) analisar, considerando protocolos, o desempenho (acertos e erros) e as representações simbólicas de alunos acerca de combinatória; (6) analisar as perspectivas do professor sobre o desenvolvimento do raciocínio combinatório, por meio de protocolos; (7) planejar uma aula que trate de resolução de problemas combinatórios.

\footnotetext{
3 A professora foi escolhida por ter participado de todos os encontros do processo formativo e das demais etapas da pesquisa. As demais professoras faltaram a algum dos encontros.

4 Trechos das entrevistas realizadas encontram-se na seção 4 do presente artigo.
} 
Na entrevista final, os três eixos se subdividem nos momentos 3 a 7, acima descritos, acrescidos de um momento de avaliação. No presente artigo, apresentamos os resultados levantados dos momentos um (1) a cinco (5), com base na comparação entre a entrevista inicial e a final.

Como afirmado anteriormente, foram propostos quatro encontros, detalhados nos quadros a seguir.

\section{Quadro 2 - Proposta de Intervenção para o Primeiro Encontro}

\begin{tabular}{|c|c|c|c|}
\hline & Objetivo & Método/Primeiro Momento & Método/Segundo Momento \\
\hline 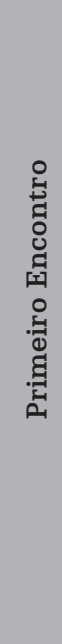 & $\begin{array}{l}\text { - Associar a combinatória } \\
\text { à teoria dos campos } \\
\text { conceituais. } \\
\text { - Identificar os tipos de } \\
\text { problemas combinatórios. } \\
\text { - Construir a ideia dos } \\
\text { invariantes de cada tipo de } \\
\text { problema combinatório. }\end{array}$ & $\begin{array}{l}\text { • Resolver problemas combinatórios } \\
\text { e, com base nas análises destes, ir } \\
\text { construindo o que são problemas } \\
\text { combinatórios. } \\
\text { • Diferenciar um problema do outro, } \\
\text { anotando as características de cada } \\
\text { um e as semelhanças e diferenças } \\
\text { entre eles. A ideia é a de que as } \\
\text { professoras possam perceber } \\
\text { os invariantes e a formadora/ } \\
\text { pesquisadora possa ir atrelando } \\
\text { essa discussão dos invariantes às } \\
\text { situações. } \\
\text { • Conversar sobre a concepção das } \\
\text { professoras acerca de combinatória } \\
\text { e sobre os tipos de problemas } \\
\text { que encontramos nesse conteúdo, } \\
\text { considerando os resultados da } \\
\text { pesquisa de Pessoa e Borba (2009). }\end{array}$ & $\begin{array}{l}\text { - Entregar quatro problemas } \\
\text { combinatórios, um de cada } \\
\text { tipo, para que os alunos } \\
\text { das professoras resolvam } \\
\text { da forma como quiserem, a } \\
\text { fim de que suas estratégias } \\
\text { possam ser discutidas no } \\
\text { próximo encontro. }\end{array}$ \\
\hline
\end{tabular}

Fonte: elaboração própria.

\section{Quadro 3 - Proposta de Intervenção para o segundo Encontro}

\begin{tabular}{|c|c|c|c|}
\hline & Objetivos & Método/Primeiro Momento & Método/Segundo Momento \\
\hline 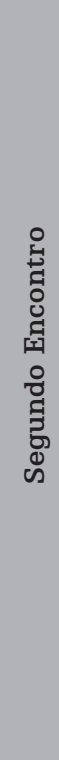 & $\begin{array}{l}\text { •Verificar possíveis } \\
\text { estratégias para resolver } \\
\text { problemas combinatórios. } \\
\text { • Trabalhar a sistematização } \\
\text { e generalização como } \\
\text { processo para melhorar } \\
\text { o desenvolvimento do } \\
\text { raciocínio combinatório. }\end{array}$ & $\begin{array}{l}\text { - Ressaltar que para resolver esse } \\
\text { tipo de problema há diferentes } \\
\text { estratégias (representações). } \\
\text { - Analisar estratégias utilizadas } \\
\text { pelos alunos das professoras e, ao } \\
\text { final, identificar as representações } \\
\text { de que estes lançaram mão. Além } \\
\text { dos protocolos dos alunos, serão } \\
\text { disponibilizados outros já estudados } \\
\text { em pesquisas anteriores. } \\
\text { - Solicitar que as professoras } \\
\text { resolvam problemas combinatórios } \\
\text { por meio de duas estratégias } \\
\text { diferentes. } \\
\text { - Discutir as diversas estratégias que } \\
\text { surgiram. }\end{array}$ & $\begin{array}{l}\text { • Mostrar protocolos de } \\
\text { resolução de aluno que: (1) } \\
\text { não usou a sistematização; } \\
\text { (2) usou a sistematização, } \\
\text { mas não generalizou; (3) } \\
\text { sistematizou e generalizou. } \\
\text { • Questionar às professoras } \\
\text { o que há de diferente nas } \\
\text { resoluções e quais são suas } \\
\text { considerações acerca dessas } \\
\text { resoluções. } \\
\text { • Destacar a sistematização } \\
\text { e a generalização realizadas } \\
\text { pelos alunos. } \\
\text { • Entregar problemas } \\
\text { combinatórios (um de cada } \\
\text { tipo) para as professoras } \\
\text { utilizarem a sistematização } \\
\text { e a generalização e, em } \\
\text { seguida, analisarmos como } \\
\text { foi feito em cada caso. }\end{array}$ \\
\hline
\end{tabular}

Fonte: elaboração própria. 


\section{Quadro 4 - Proposta de Intervenção para o Terceiro Encontro}

\begin{tabular}{|c|c|c|}
\hline 운 & Objetivo & Método/Primeiro Momento \\
\hline 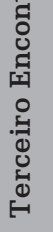 & $\begin{array}{l}\text { • Elaborar um planejamento } \\
\text { de aula tendo em vista as } \\
\text { considerações trabalhadas } \\
\text { nos encontros anteriores. }\end{array}$ & $\begin{array}{l}\text { - Preparar aula sobre combinatória, enfatizando o tripé de Vergnaud } \\
\text { (invariantes, situações e representações) e levando em consideração } \\
\text { a estratégia mais utilizada pelos alunos até então pesquisados (a } \\
\text { listagem de possibilidades), a sistematização e a generalização. } \\
\text { • Lembrar que a explicitação dos invariantes é importante e ne- } \\
\text { cessária. }\end{array}$ \\
\hline
\end{tabular}

Fonte: elaboração própria.

\section{Quadro 5 - Proposta de Intervenção para o Quarto Encontro}

\begin{tabular}{|c|c|c|}
\hline & Objetivo & Método/Primeiro Momento \\
\hline 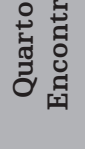 & $\begin{array}{l}\text { - Analisar coletivamente a } \\
\text { aplicação do planejamento } \\
\text { realizada pelos professores. }\end{array}$ & $\begin{array}{l}\text { - Conversar com as professoras sobre as principais facilidades e } \\
\text { dificuldades na aplicação de seus planejamentos, a fim de que elas } \\
\text { analisem e discutam sua prática considerando todo o processo } \\
\text { realizado durante a formação. }\end{array}$ \\
\hline
\end{tabular}

Fonte: elaboração própria.

\section{Nossos resultados: o que conseguimos verificar}

\subsection{Formação e experiência docente da participante da pesquisa}

A professora entrevistada possui uma formação docente bastante ampla (licenciatura em Pedagogia e em Física e duas especializações) e muito tempo de atuação profissional - fatores que podem estar presentes em sua prática.

Com relação às experiências e aos fatos da vida escolar, incluindo aqueles concernentes à matemática, a professora analisada não deixa claro em que momento de sua vida escolar estudou combinatória, contudo, conseguimos perceber um conhecimento prévio desse conteúdo em sua fala, quando destacou a vivência com produto cartesiano, citando o problema clássico de combinação de roupas, trabalhado nos anos iniciais do EF.

\subsection{Sobre o conhecimento do conteúdo de combinatória}

Em outro momento das entrevistas, solicitou-se que a professora classificasse os diferentes problemas (situações) apresentados e, em seguida, as características (invariantes) de cada tipo de problema. Para isso, foram entregues quatro problemas de combinatória, retirados de Pessoa e Borba (2009) e de Pessoa e Santos (2011), na entrevista inicial, e de Azevedo, Costa e Borba (2011), na entrevista final.

Entre as reflexões da docente, na entrevista inicial, sobre o conhecimento das diferentes situações dos problemas combinatórios, 
destacamos os extratos do problema de permutação (Quadro 6). Contudo, apesar de apresentarmos somente o extrato de um tipo de problema, será realizada a análise sobre o conhecimento da professora com relação a todos os tipos de problemas.

\section{Quadro 6 - Entrevista Inicial, Classificação dos Problemas quanto às suas Situações (Permutação)}

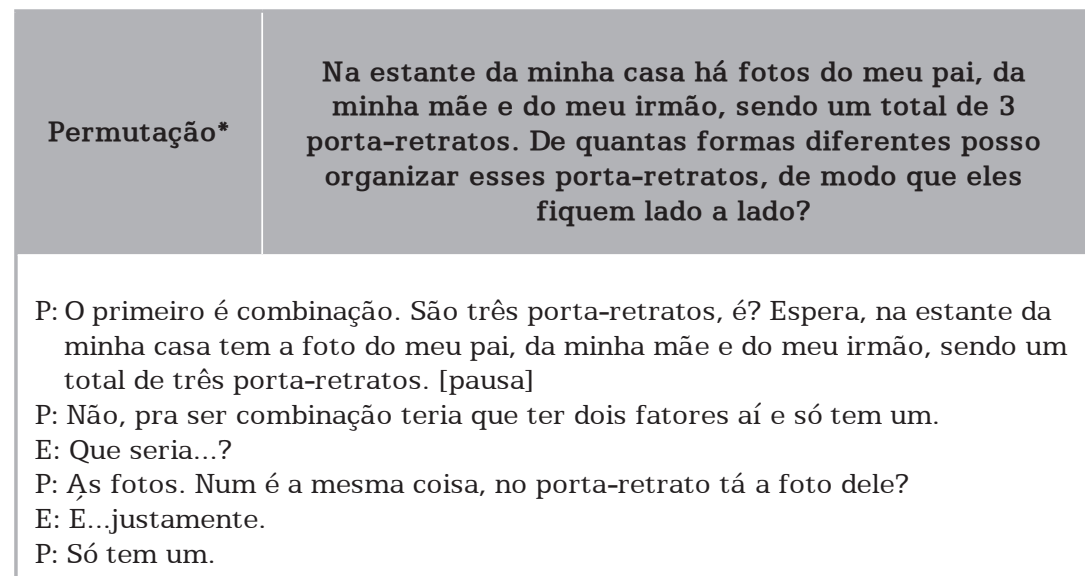

* O tipo de problema (situação) está aqui explicitado para situar o leitor, entretanto, na entrevista, esse dado foi omitido à professora.

Fonte: elaboração própria.

A professora demonstra considerar que o conteúdo matemático combinatória tem somente um tipo de problema, o produto cartesiano, aparentando, assim, não ter clareza em relação aos problemas combinatórios apresentados. Contudo, como pode ser observado no Quadro 6, a professora denomina esses tipos de problemas de combinação, não demonstrando compreender que combinação é apenas um tipo de problema combinatório. Acreditamos que isso se deve à nomenclatura do conteúdo, que pode induzir a um pensamento equivocado de que o termo combinação é um sinônimo para o conteúdo combinatória.

Entende-se que o mais importante não é, necessariamente, saber denominar os tipos de problemas, mas entender suas características, pois cada situação exige uma forma diferente de raciocínio. No entanto, nesse momento, percebemos que, além da dificuldade em denominá-los, aparentemente não há clareza o bastante acerca das características que os diferenciam.

Considerando os mesmos problemas combinatórios utilizados no momento anterior, solicitou-se que a professora identificasse as características que conceituam cada problema apresentado.

No Quadro 7, destacamos o conhecimento da professora com relação aos invariantes dos problemas de permutação. Nesse momento, a professora deveria dizer quais características percebia em cada um dos problemas apresentados. 


\section{Quadro 7 - Entrevista Inicial, Classificação dos Problemas quanto aos seus Invariantes (Permutação)}

\begin{tabular}{|l|l|} 
Permutação & $\begin{array}{c}\text { Na estante da minha casa há fotos do meu pai, da } \\
\text { minha mãe e do meu irmão, sendo um total de 3 porta- } \\
\text { retratos. De quantas formas diferentes posso organizar } \\
\text { esses porta-retratos de modo que eles fiquem lado } \\
\text { a lado? }\end{array}$ \\
\begin{tabular}{|l} 
P: O primeiro é a posição do quadro. \\
$\begin{array}{l}\text { E: Dos porta-retratos... } \\
\text { P: Lado a lado... são três, podia colocar um no primeiro, no meio e no fim e } \\
\text { depois trocar de lado. }\end{array}$
\end{tabular} \\
\hline
\end{tabular}

Fonte: elaboração própria.

Pudemos verificar que alguns invariantes contidos nos problemas combinatórios conseguem ser percebidos pela professora, mesmo que não claramente, tal como exemplifica o Quadro 7. Ao analisarmos a percepção da professora para além do problema apresentado no quadro, observamos que a docente não conseguiu encontrar nenhum invariante do problema de arranjo, nem quando comparado ao problema de combinação, que fora analisado por ela anteriormente.

Outro dado a ser discutido é que a professora consegue perceber que o problema de produto cartesiano é o mais comum. Mesmo não sabendo nomeá-lo, ela consegue perceber que este tipo é bastante utilizado nos anos iniciais do EF, o que é confirmado pela pesquisa de Barreto, Amaral e Borba (2007). Assim, consideramos, com base nessa percepção, que, mesmo implicitamente, a professora consegue distinguir algumas características dos problemas, bem como diferenciar o tipo de problema mais utilizado no nível de ensino em que atua.

Após os encontros de formação, na entrevista final, pudemos constatar um grande avanço da professora quanto ao conhecimento do conteúdo. Considerando a entrega de quatro problemas combinatórios para análise da professora durante a entrevista final, destacam-se, no Quadro 8, os extratos das inferências realizadas sobre diferentes situações e invariantes combinatórios do problema de permutação. Quanto à entrevista inicial, apresentamos quadros diferentes para as análises das situações e dos invariantes pela professora, ao passo que, quanto à entrevista final, não houve separação, porque a professora diferencia os tipos de problemas (situações) justamente baseando-se nos invariantes que os diferenciam.

\section{Quadro 8 - Entrevista Final, Classificação dos Problemas quanto às suas Situações e Invariantes (Permutação)}

\begin{tabular}{|c|c|}
\hline Permutação & $\begin{array}{c}\text { De quantas maneiras possíveis pode-se escrever } \\
\text { números de quatro algarismos diferentes, usando os } \\
\text { algarismos } 3,5,7 \text { e } 9 ?\end{array}$ \\
\hline \multicolumn{2}{|c|}{$\begin{array}{l}\text { [a docente lê o quarto problema e começa a listar as possibilidades] } \\
\text { P: Eu tenho que usar os mesmos quatro... usar os quatro. Então... aqui tô } \\
\text { usando todos [referindo-se ao problema de permutação]. Lá tá de dois em dois... } \\
\text { [referindo-se aos problemas de combinação]. } \\
\text { P: Gera possibilidades! Já saquei! [risos] }\end{array}$} \\
\hline
\end{tabular}

Fonte: elaboração própria. 
De modo distinto da observação de que a professora denominava combinação todos os problemas combinatórios, após a intervenção percebe-se que todas as situações já são entendidas. Como visto no Quadro 8, na entrevista inicial, a professora já mencionava alguns invariantes, mesmo que não explicitamente, enquanto, na entrevista final, os invariantes são notados mais claramente. Embora a docente ainda apresente dúvidas na análise, consegue chegar à classificação correta por exclusão e comparação.

A professora ainda analisou os problemas segundo seu nível de dificuldade, destacando, na entrevista inicial, que o problema de permutação era um dos de mais fácil resolução para seus alunos ( $1^{\circ}$ ano do EF) e os de arranjo e produto cartesiano apresentavam maior grau de dificuldade, apesar de identificar, em um momento anterior, o produto cartesiano como um dos problemas combinatórios mais comuns em sala de aula.

Na entrevista final, pôde-se verificar uma mudança concernente ao nível de dificuldade dos problemas combinatórios. A docente passa a identificar o produto cartesiano como a situação de mais fácil compreensão para os alunos e a permutação como a de maior nível de dificuldade. Ainda ressalta que o enunciado pode ser um complicador na resolução do problema. Essa nova percepção quanto à dificuldade está em acordo com estudos anteriores, como o de Pessoa e Borba (2009, 2010), Correa e Oliveira (2011) e Azevedo e Borba (2012).

\subsection{Sobre o conhecimento didático de combinatória}

Nesta fase da entrevista, foram investigados os conhecimentos matemáticos e didáticos da professora a respeito do tema combinatória para, assim, entender como a professora pesquisada compreende e procede em relação ao ensino desse conteúdo nos anos iniciais, especificamente, no $1^{\circ}$ ano do EF.

Sobre sua prática docente com relação ao conteúdo, na entrevista inicial, foi observado que a docente acreditava não ser possível trabalhar combinatória no $1^{\circ}$ ano do EF, tampouco na educação infantil. A professora ressaltava que, por atuar no $1^{\circ}$ ano do $\mathrm{EF}$, não era possível trabalhar esse conteúdo com sua turma e ressalvava a possibilidade de o trabalho ser iniciado a partir do $2^{\circ}$ ano do $\mathrm{EF}$, com o uso exclusivo do produto cartesiano.

Diferentemente das falas anteriores, na entrevista final, a professora acreditava que o ensino de combinatória a alunos dos primeiros anos do EF tem que ser realizado em longo prazo, como defendido por Vergnaud (1986).

Estudos recentes mostram que é possível trabalhar combinatória com alunos dos anos iniciais, como demonstram as pesquisas de Pessoa e Santos (2011) e Azevedo, Costa e Borba (2011). Pesquisadoras como Santos, Matias e Pessoa (2011) e Pessoa e Borba (2012), em estudo realizado com alunos da educação infantil, destacam a possibilidade de compreensão dos invariantes combinatórios. O estudo realizado por Barreto, Amaral e Borba (2007) analisa livros didáticos dos anos iniciais e o manual do professor, mostrando que os diferentes problemas combinatórios são abordados nos 
livros didáticos dos anos iniciais do EF, sem que, no manual e nas orientações ao longo do livro, o professor seja instruído de que se trata de problemas diferentes e, que, portanto, devem ter um olhar mais cuidadoso.

\subsubsection{Análise do desempenho e das representações simbólicas de alunos}

Nas entrevistas, propôs-se que a docente refletisse sobre alguns protocolos de resolução de problemas combinatórios por alunos, a fim de que ela analisasse o desempenho (acertos e erros) e as representações simbólicas deles. Ocorreu ainda a reflexão acerca das dificuldades que poderiam ter causado os erros e dos caminhos que poderiam ser trilhados para ajudar tais alunos a progredirem.

A percepção da professora quanto aos possíveis erros e estratégias utilizadas pelos alunos melhorou após os encontros de formação, haja vista o aprofundamento de suas análises e a aplicação, caso a caso, das reflexões suscitadas na formação.

Na entrevista inicial, a docente analisou protocolos de resolução de problemas combinatórios pelos alunos, como o que apresentamos na Figura 1.

Sem repetir as letras na mesma palavra, quantas palavras diferentes (com ou sem sentido) podemos formar com as letras da palavra GATO?

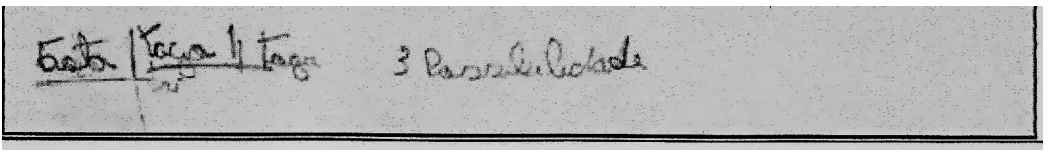

Figura 1 - Protocolo de Resolução de Aluno (Permutação)

Fonte: Pessoa e Santos (2012b).

Destacamos uma passagem da análise com base em protocolos de problema de permutação e que traz reflexão da professora na entrevista inicial:

P: Ele só fez alterar... no lugar dele fazer alguma conta, ele fez a possibilidade de trocar as letras, ele trocou as letras, escrevendo.

Ainda que a docente reconheça a validade da estratégia, utilizada pelo aluno, de trocar as letras da palavra e fazer uma listagem, ela legitima a resolução do problema por meio de conta. Possivelmente essa análise está baseada nas experiências tanto como professora quanto como aluna de que questões matemáticas se resolvem com contas. Para Tardif (2008) e Gauthier (1998), os saberes experienciais fazem parte da base dos saberes necessários à docência. Tardif dá ênfase a esses saberes, acreditando que eles passam a existir na e pela prática, sendo atrelados à construção da habilidade docente. 
A docente não faz referência aos acertos e erros. Observa-se, na Figura 1, que o aluno, apesar de não esgotar todas as possibilidades, parece perceber os invariantes desse tipo de problema combinatório. De acordo com Pessoa e Santos (2012b), este aluno, além de utilizar todos os elementos fornecidos, modifica a ordem na qual eles são apresentados.

Na entrevista final, a docente também foi convidada a analisar alguns protocolos de resolução de problemas combinatórios por alunos, como o que vemos na Figura 2.

Quantas palavras diferentes (com ou sem sentido) podemos formar usando as letras da palavra AMOR?

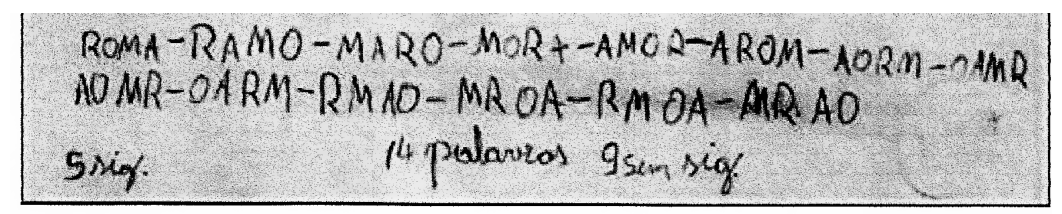

Figura 2 - Protocolo de Resolução de Aluno (Permutação)

Fonte: Pessoa e Borba (2009).

Apresentamos a sinopse da análise realizada pela docente sobre os possíveis erros dos alunos durante a entrevista final:

[a docente lê o problema]

P: É a questão das tentativas mesmo... é que eu esqueço como é que se diz quando a pessoa vai fazendo um por um. Qual o nome que se dá? Diagrama? Sei lá... ela tinha que primeiro organizar pra depois dar a resposta.

P: Produto cartesiano mesmo, você pode multiplicar logo de uma vez. Quando a criança consegue logo de uma vez e faz a conta, eu acredito que [interrompe a fala]... se bem que acho que seja mais fácil com o produto cartesiano, os outros acho que é melhor fazer assim [referindose à listagem].

A docente verifica que o aluno resolveu de forma correta o problema, mesmo não esgotando todas as possibilidades, como destacado por Pessoa e Borba (2009) em seu estudo. De acordo com Batanero, Godino e NavarroPelayo (1996), a falta de resolução sistemática dos casos possíveis pode ser um agravante no não esgotamento das possibilidades, sendo um dos erros mais comuns durante as resoluções de problemas combinatórios.

A professora verifica que o aluno utilizou-se de uma representação válida para resolver o problema. Ela acredita, durante um momento, que se o aluno respondesse por multiplicação direta conseguiria alcançar a resposta mais facilmente, contudo, percebe, logo em seguida, que tal representação só é válida com problemas de produto cartesiano.

A professora ainda foi questionada sobre quais representações simbólicas seus alunos poderiam utilizar para resolver problemas combinatórios. Ela destacou, mantendo sua ideia inicial, as seguintes 
formas de representação: a forma escrita, com a utilização do desenho, e o material manipulável.

Quando pensa no trabalho com seus alunos, a professora pondera a possibilidade de formas de ensino e, principalmente, de estratégias alternativas para a resolução, em diálogo com Borba (2010), que ressalta a importância de aproveitar as estratégias espontaneamente desenvolvidas pelos estudantes durante o processo de ensino e aprendizagem.

Quanto à possibilidade de atividades que utilizem o material manipulável como ferramenta para facilitar a aprendizagem do aluno, Guirado e Cardoso (2007) apontam que, mesmo que o conteúdo de combinatória seja trabalhado com maior ênfase no ensino médio, é possível inseri-lo desde os anos iniciais do EF por meio desse material, em consonância com esquemas, tabelas, diagramas ou desenhos. Pesquisa realizada por Santos, Matias e Pessoa (2011) revela que o uso desse material viabiliza o ensino de combinatória, especificamente para alunos dos anos iniciais, além de poder contribuir para a construção dos conhecimentos matemáticos da criança. Com relação aos problemas combinatórios trabalhados, as autoras observaram que o material manipulável e os enunciados, tratando de algumas situações cotidianas dos alunos, contribuíram para a percepção dos invariantes.

De modo geral, ao compararmos as respostas e análises da professora nas entrevistas inicial e final, percebemos que houve uma ressignificação de seu conhecimento. A docente passa da percepção de um único tipo de problema (produto cartesiano, que ela, equivocadamente, denomina de combinação) na entrevista inicial para o estabelecimento de relação entre os quatro diferentes tipos de problema na entrevista final, refletindo sobre os invariantes e preocupando-se com a escolha e a ordem dos elementos para a definição das questões. A docente reflete também sobre as diferentes representações utilizadas pelos alunos, mesmo que ainda não saiba definilas, enfatizando o uso da sistematização e generalização.

Verifica-se, então, que a formação realizada contribuiu para construir o conceito, principalmente na distinção das diferentes situações e seus invariantes, além de avançar nas reflexões sobre as diferentes formas de representação e no desenvolvimento do raciocínio combinatório.

\section{Considerações finais}

Os dados analisados indicam a necessidade de formação continuada em combinatória, tendo em vista a limitação atinente ao conhecimento do conteúdo e ao conhecimento didático do conteúdo por parte da professora.

A compreensão da docente com relação ao conteúdo abordado nas entrevistas realizadas (inicial e final) equivale à de professores da educação básica, que acreditam não ser possível trabalhar combinatória no $1^{\circ}$ ano do $\mathrm{EF}$, como constatado também junto às demais professoras que participaram do processo formativo. Mesmo assim, a professora nos mostra, em algumas falas, acreditar que quanto mais cedo um conteúdo for apresentado ao aluno, mais fácil e rápida será sua apreensão. Esse pensamento da professora, 
de certa forma, se assemelha ao que defendem Pessoa e Borba (2009), que acreditam ser possível o trabalho com combinatória desde os anos iniciais do EF, e Santos, Matias e Pessoa (2011), que mostram que alunos da educação infantil já são capazes de perceber alguns dos invariantes de problemas combinatórios.

Na diferenciação e classificação dos problemas combinatórios, percebe-se que a docente demonstrava dificuldade, visto que conhecia apenas um tipo de problema combinatório, o produto cartesiano, apesar de chamá-lo de combinação. Acreditamos que a dificuldade da professora se deve à nomenclatura do conteúdo, que pode induzir ao equívoco de pensar que o termo combinação é um sinônimo para o conteúdo combinatória. Com relação aos invariantes contidos nas diferentes situações combinatórias, alguns são notados em diferentes situações, mesmo que não claramente.

Após os momentos de formação, a docente passou a refletir mais claramente sobre os problemas, analisando suas situações e invariantes e conseguindo estabelecer relações entre os diferentes tipos de problemas, com base nas características de cada um.

Percebe-se, ainda, durante as entrevistas, que a docente reconhece o desenho como uma representação simbólica válida para ser utilizada pelos seus alunos e o material manipulável como uma forma de representação que possa facilitar a aprendizagem. Apesar disso, em alguns momentos, a professora destaca a possibilidade do uso do algoritmo. Não estamos defendendo o não uso dos algoritmos; ao contrário, acreditamos que a fórmula e os algoritmos são sínteses de um conceito, os quais facilitam a resolução de problemas referentes a esse conceito, entretanto, como discutido por Borba (2010), é preciso valorizar as diferentes formas de representações simbólicas que podem e devem ser utilizadas, sobretudo em situações com problemas que levam a um menor número de possibilidades em qualquer nível escolar ou em qualquer situação de vida, bem como no início do trabalho com o conceito, ou seja, antes da formalização.

Um aspecto observado é a aprendizagem que ocorreu entre as entrevistas. No início, a docente afirmava não ser possível trabalhar esse conteúdo com seus alunos, pois estes pertenciam ao $1^{\circ}$ ano, mas, na entrevista final, passou a defender que quanto mais cedo for iniciado o trabalho com um conteúdo, melhor será o aproveitamento do aluno. Além disso, no início das análises sobre as produções dos alunos, ela demonstrava valorizar o uso de conta para a resolução, porém, no decorrer da entrevista final, passou a demonstrar um novo olhar sobre as estratégias apresentadas pelos alunos. Também na entrevista final verificamos a constante reflexão por parte da docente antes de analisar as situações e os invariantes combinatórios, o que demonstra aprendizagem durante a própria entrevista.

Os resultados mostram que a formação continuada em combinatória, baseada nas situações, nos invariantes e nas representações simbólicas, é uma ação importante, pois ajudou a professora a refletir sobre esse conteúdo, que deve ser trabalhado desde os anos iniciais, tanto por sua importância no desenvolvimento do raciocínio lógico, como afirma Borba (2010), quanto por sua presença nos livros didáticos de matemática dos 
anos iniciais do EF (Barreto; Amaral; Borba, 2007), além de seu ensino ser orientado pelos PCN desde 1997. A combinatória ainda é negligenciada na prática provavelmente devido à falta de aprofundamento conceitual por parte de alguns professores.

\section{Referências bibliográficas}

AZEVEDO, J.; COSTA, D. M.; BORBA, R. O impacto do software Árbol no raciocínio combinatório. In: CONFERENCIA INTERAMERICANA DE EDUCAÇÃO MATEMÁTICA, 13., 2011, Recife. Anais... Recife: Universidade Federal de Pernambuco, 2011.

AZEVEDO, J.; BORBA, R. O ensino da Combinatória por meio da construção de Árvores de Possibilidades com e sem o uso do software Diagramas de Árbol. In: ENCONTRO BRASILEIRO DE ESTUDANTES DE PÓS-GRADUAÇÃO EM EDUCAÇÃO MATEMÁTICA, 16., 2012, Canoas. Anais... Canoas: Universidade Luterana do Brasil, 2012.

BARRETO, F.; AMARAL, F.; BORBA, R. Como o raciocínio combinatório tem sido apresentado em livros didáticos de séries iniciais. Caderno de Trabalhos de Conclusão de Curso de Pedagogia, Recife, v. 2, p. 1-21, 2007.

BATANERO, C.; GODINO, J.; NAVARRO-PELAYO, V. Razonamiento combinatorio. Madrid, Espanha: Editorial Síntesis, 1996.

BORBA, R. O raciocínio combinatório na educação básica. In: ENCONTRO NACIONAL DE EDUCAÇÃO MATEMÁTICA, 10., 2010, Salvador. Anais... Salvador: SBEM, 2010.

BRASIL. Ministério da Educação (MEC). Secretaria do Ensino Fundamental (SEF). Parâmetros Curriculares Nacionais: matemática: $1^{\text {a }}$ a $4^{\text {a }}$ série. Brasília, DF: MEC/SEF, 1997.

CORREA, J.; OLIVEIRA, G. A escrita do problema e sua resolução: o entendimento intuitivo acerca da combinatória. Educar em Revista, Curitiba, n. esp., p. 77-91, 2011.

FUSARI, J. C. A formação continuada de professores no cotidiano da escola fundamental. São Paulo: I-DE, 1992. (Série Idéias, n. 12). Disponível em: <http://www.crmariocovas.sp.gov.br/pdf/ideias_12_ p025-034_c.pdf >. Acesso em: 14 set. 2011.

GAUTHIER, C. Por uma teoria da pedagogia: pesquisas contemporâneas sobre o saber docente. Ijuí: Unijuí, 1998. 
GUIRADO, J. C.; CARDOSO, E. Análise combinatória: da manipulação à formalização de conceitos. In: ENCONTRO PARANAENSE DE EDUCAÇÃO MATEMÁtiCA, 9., 2007, Assis Chateubriand. Anais... Assis Chateubriand: SBEM, 2007.

PESSOA, C.; BORBA, R. Quem dança com quem: o desenvolvimento do raciocínio combinatório de crianças de $1^{\mathrm{a}}$ a $4^{\mathrm{a}}$ serie. Zetetike: Revista de Educação Matemática, Campinas, v. 17, n. 31, jan./jun. 2009.

PESSOA, C.; BORBA, R. O Raciocínio Combinatório do início do Ensino Fundamental ao término do Ensino Médio. In: ENCONTRO NACIONAL DE EDUCAÇÃO MATEMÁTICA, 10., 2010, Salvador. Anais... Salvador: SBEM, 2010.

PESSOA, C.; BORBA, R. Do young children notice what combinatorial situations require? In: CONFERENCE OF THE INTERNATIONAL GROUP FOR THE PSYCHOLOGY OF MATHEMATICS EDUCATION, 36., 2012, Tapei, Taiwan. Proceedings... Taipei, Taiwan: First Girls High School, 2012.

PESSOA, C.; SANTOS, L. T. O que fazem alunos do $5^{\circ}$ ano de escolarização básica diante de situações combinatórias? In: CONFERÊNCIA INTERAMERICANA DE EDUCAÇÃ̃ MATEMÁTICA, 13., 2011, Recife. Anais... Recife: SBEM, 2011.

PESSOA, C.; SANTOS, L. Gato, Gota, Toga... A Combinatória no $5^{\circ}$ ano do ensino fundamental. UNOPAR Científica Ciências Humanas e Educação, Londrina, v. 13, n. 2, p. 35-48, out. 2012a.

PESSOA, C.; SANTOS, L. Estudo de caso: como duas crianças passam a compreender a combinatória a partir de intervenções? Revista Eletrônica de Educação, São Carlos, SP, v. 6, p. 358-382, 2012b.

ROCHA, C. de A. Formação docente e o ensino de problemas combinatórios: diversos olhares, diferentes conhecimentos. 2011. $191 \mathrm{f}$. Dissertação (Mestrado em Educação Matemática e Tecnológica) - Centro de Educação, Universidade Federal de Pernambuco, Recife, 2011.

SANTOS, M.; MATIAS, P.; PESSOA, C. O Raciocínio Combinatório na Educação Infantil. 2011. Trabalho de Conclusão de Curso (Graduação em Pedagogia) - Centro de Educação, Universidade Federal de Pernambuco, Recife, 2011.

SANTOS, L.; PESSOA, C. A influência do contexto e do tipo de problema na compreensão de problemas combinatórios por alunos do $5^{\circ}$ ano do ensino fundamental. Educação Matemática em Revista, Florianópolis, v. 43 , p. $40-48,2014$. 
SHULMAN, L. S. Conocimiento y enseñanza: fundamentos de la nueva reforma. Profesorado: revista de currículum y formación del profesorado.

Granada, Espanha, v. 9, n. 2, p.1-30, 2005.

TARDIF, M. Saberes docentes e formação profissional. 9. ed. Petrópolis:

Vozes, 2008.

VERGNAUD, G. Psicologia do desenvolvimento cognitivo e didática das matemáticas: um exemplo: as estruturas aditivas. Análise Psicológica,

[Lisboa, Portugal], v. 5, n. 1, p. 75-90, 1986.

Recebido em 24 de julho de 2014.

Solicitação de correções em 24 de março de 2015.

Aprovado em 18 de maio de 2015. 